Landslides (2018) 15:1-3 DOI 10.1007/s10346-017-0928-2

Received: 19 November 2017

Accepted: 20 November 2017

Published online: 9 December 2017

c) Springer-Verlag GmbH Germany,

part of Springer Nature 2017

\section{K. Sassa}

\section{Monthly publication of Landslides: Journal of International Consortium on Landslides (ICL)}

Landslides: Journal of the International Consortium on Landslides (ICL) has moved to a monthly journal starting January 2018. The ongoing progress of Landslides, categories of articles, and the contribution of the journal to global initiatives for landslide disaster risk reduction are presented.

Progress of Landslides: Journal of the International Consortium on Landslides

The initiation of Landslides: Journal of the International Consortium on Landslides was proposed at the foundation meeting of the International Consortium on Landslides held in Kyoto on 21-25 January 2002. The establishment of the Landslides journal was adopted as the first coordinating project of the International Programme on Landslides (IPL-C10o) at the first session of the Board of Representatives of ICL held at UNESCO Headquarters on 19-21 November 2002. After consultation with several publishing companies, ICL agreed with Springer, Heidelberg, to publish a new full-color journal "Landslides: Journal of the International Consortium on Landslides" in 2003. The initial issue of Landslides was published in April 2004 supported by a Grant-in-Aid from the Japan Society for the Promotion of Science (JSPS) and the World Meteorological Organization (WMO).

Landslide phenomena are studied by many fields of sciences: geology, geomorphology, geotechnical engineering, geophysics, forest engineering, and social sciences, and research results are published in various related journals and other formats. Terminologies in each field are not always the same although the definition of landslides and their types were generally agreed during the International Decade for Natural Disaster Reduction (IDNDR) and were published by Cruden and Varnes (1996). Highland and Bobrowsky (2017) recently published TEXT-tool o.001-2.1 Landslide Types: Description, Illustration and Photos in the ISDR-ICL Landslide Interactive Teaching Tools to provide a readily accessible and user-friendly visual summary of landslide technologies.

Landslides is a full-color journal including full-color photos and full-color geological maps. Full-color photos of landslides are a common information source for landslides that are made understandable for all readers, scientists in different fields, engineers, practitioners, and policymakers. No contribution fee and no full-color printing fee are charged to promote contributions from less developed countries and young researchers.

Progress of Landslides is shown in Fig.1 in terms of the number of pages/year, the number of articles/year, and the impact factor. The annual number of pages has continuously increased from 323 pages in 2004 to 2162 pages in 2017, and the number of articles has risen from 37 to 161 over the same period. The impact factor has increased from 0.986 in 2007 to 3.657 in 2016. The number of issues/year was 4 from 2004 to 2012 (9 years from vol. 1 to vol. 9) and then 6 from 2013 to 2017 (5 years from vol. 10 to vol. 14). From January 2018 (vol. 15) onwards, it will consist of 12 issues/year, namely a monthly journal.

\section{Categories of articles for Landslides}

Landslides has different categories of articles with specific objectives.

1. Original papers (6-12 pages): original research and investigation results. Two reviewers and one editor evaluate the paper. These contributions require the highest degree of originality.

2. Review papers (6-12 pages): review of current research and development of technology in a thematic area of landslide studies.

3. Recent landslides (less than 6 pages): reports of recent landslides including location (latitude/longitude), plan, section, geology, volume, movement, mechanism, and disasters within available extent. This will be unique for Landslides. Reports of landslides occurring in developing countries are less published in other journals. Information of new landslides in various regions of the world are important for the landslide community. Landslides encourages contribution from less developed countries. One reviewer and one editor evaluate the article.

4. Technical note (less than 6 pages): research notes, review notes, case studies, progress of technology, and best practice in monitoring, testing, investigation, and mitigation measures. Case studies from less developed countries are included in this category. One reviewer and one editor evaluate the article.

5. Discussion (less than 3 pages): discussion on published articles.

6. ICL/IPL activities (less than 6 pages): progress of IPL projects, World Centres of Excellence on Landslide Risk Reduction (WCoEs), and other ICL-IPL activities including preparatory activities of the planed Kyoto 2020 Commitment.

7. News, book review, and others.

Landslides is a monthly journal beginning in January 2018. Monthly global information dissemination can be regarded as a newsletter. ICL wishes to intensify the category of ICL/IPL activities and news as the core information platform for the ISDR-ICL Sendai Partnerships 2015-2025, the Sendai Framework 2015-2030, and the planned Kyoto 2020 Commitment.

\section{Contribution of Landslides to global initiatives}

Landslides was the initial coordinating project of the International Programme on Landslides (IPL) which is a program of ICL to the International Strategy for Disaster Reduction (ISDR) (Han et al. 2017). Landslides contributes to the ISDR-ICL Sendai Partnerships 2015-2025 for global promotion of understanding and reducing landslide disaster risk which was adopted on 16 March 2015 in Sendai during the World Conference on Disaster Risk Reduction 


\section{Editorial}

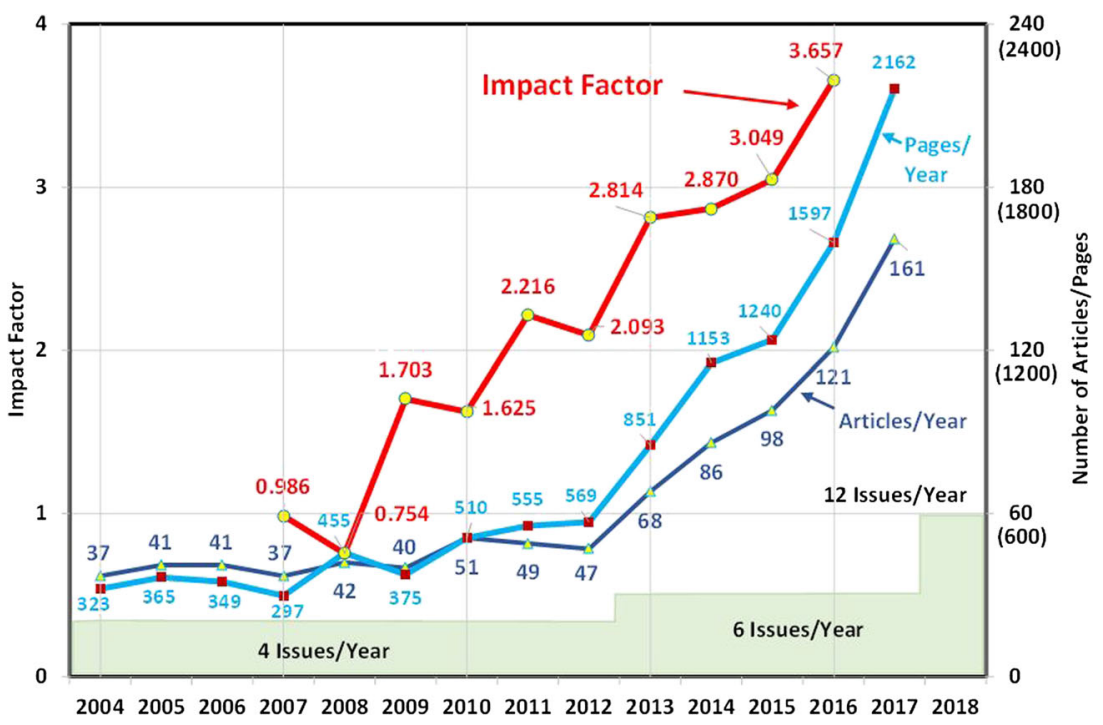

Fig. 1 Progress of landslides from its foundation in 2004 to 2018

(WCDRR) (Sassa 2015). The Sendai Partnerships is a voluntary commitment to WCDRR and the 2030 Agenda Sustainable Development Goals, especially goal 11 "Make cities and human settlements inclusive, safe, resilient and sustainable."

A high-level panel discussion was organized on 30 May 2017 during the Fourth World Landslide Forum in Ljubljana, Slovenia (Mikos et al. 2017). It was chaired by Jakob Rhyner (Vice Rector of the United Nations University) and moderated by Kaoru Takara (ICL Treasurer and Director of the Disaster Prevention Research Institute, Kyoto University) with panelists from various Sendai Partnerships signatory organizations. A total of 608 participants from 49 countries/regions, 4 United Nations organizations, and 5 other international organizations formally adopted the $2017 \mathrm{Lju}-$ bljana Declaration on landslide risk reduction and the Kyoto 2020 Commitment for global promotion of understanding and reducing landslide disaster risk (Sassa 2017a and 2017b).

The Kyoto 2020 Commitment for global promotion of understanding and reducing landslide disaster risk to the ISDR-ICL Sendai Partnerships 2015-2025, the Sendai Framework for Disaster Risk Reduction 2015-2030, and the 2030 Agenda-Sustainable Development Goals is now planned to develop the Sendai Partnerships 2015-2025 as a wider and more stable global framework to mobilize in the medium and long terms a global alliance which will accelerate and incentivize action for landslide disaster risk reduction to 2025,2030 , and beyond.

Global landslide disaster risk reduction will be effectively achieved by the joint efforts of scientists, engineers, practitioners, and policymakers from both developed and developing countries. The monthly journal Landslides will be the core platform for cooperation within all participating parties of the Kyoto 2020 Commitment. All participating parties are invited to report their activities contributing to landslide risk reduction in the category of ICL/IPL activities. A new ICL membership category, "ICL associates" was created in 2017 in addition to the ICL members and ICL supporters in an attempt to expand the diversity of ICL memberships. The ICL memberships and benefits are presented in
Sassa (2017b) and also on the ICL web <http://icl.iplhq.org/category/icl/registration-and-benefits/>.

The progress of land development due to urbanization and the expansion of human settlements to mountains over the world will demand that landslide disaster risk reduction research and coordinated actions across the globe continue well after 2025 and 2030. ICL and IPL groups continue to organize the triennial World Landslide Forum together with numerous scientists, engineers, practitioners, and policymakers. The Fifth World Landslide Forum (WLF5) will be organized on 2-6 November 2020 in Kyoto, Japan. The Kyoto 2020 Commitment will be established at the WLF5 and will be reviewed and updated at each of the forthcoming triennial World Landslide Forums. WLF5 is introduced in Sassa (2017c) and on the WLF5 website <http://wlf5.iplhq.org/>.

\section{References}

Cruden D, Varnes D (1996) Landslide types and processes. Landslides-investigation and mitigation (editors: K. Turner and R. Schuster), Special Report 247, Transportation Research Board, National Research Council, National Academy Press, pp 36-75

Han Q, Sassa K, Kan FM, Margottini C (2017) International Programme on Landslides (IPL): objectives, history and list of world centres of excellence and IPL projects. In: Sassa K, Mikos M, Yin Y (eds) Advancing culture of living with landslides, Vol.1 ISDRICL Sendai Partnerships 2015-2025, Springer, (the whole volume is free access and download), pp 229-245. https://doi.org/10.1007/978-3-319-59469-9_19

Highland L, Bobrowsky P (2017) TEXT-tool 0.001-2.1 "Landslide types: description, illustration and photos". Landslide dynamics: ISDR-ICL landslide teaching tools (editors: K. Sassa, Guzzetti F, Yamagishi H, Arbanas Z, Casagli N, McSaveney M, Dang K), Vol.1 fundamentals, mapping and monitoring, Springer, pp 1-38

Mikos M, Yin Y, Sassa K (2017) The Fourth World Landslide Forum, Ljubljana, 2017. Landslides 14(5):1843-1854. https://doi.org/10.1007/s10346-017-0889-5

Sassa K (2015) ISDR-ICL Sendai Partnerships 2015-2025 for global promotion of understanding and reducing landslide disaster risk. Landslides 12(4):631-640. https:// doi.org/10.1007/s10346-015-0586-1

Sassa K (2017a) The 2017 Ljubljana Declaration on landslide risk reduction and the Kyoto 2020 Commitment for global promotion of understanding and reducing landslide disaster risk. Landslides 14(4):1289-1296. https://doi.org/ $10.1007 /$ s10346-017-0857-0 
Sassa K (2017b) Participants in the Fourth World Landslide Forum and call for ICL members, supporters, and associates. Landslides 14(5):1839-1842. https://doi.org/ $10.1007 / \mathrm{s} 10346-017-0858-z$

Sassa K (2017c) The Fifth World Landslide Forum -implementing and monitoring the ISDR-ICL Sendai Partnerships. Landslides 14(5):1857-1859. https://doi.org/10.1007/ s10346-017-0859-y

\section{K. Sassa $(\varangle)$}

International Consortium on Landslides (ICL),

Kyoto, Japan

Email: secretariat@iclhq.org 